\title{
DESIGNING AND BUILDING A KNOWLEDGE WAREHOUSE ORIENTED, PUBLIC DECISION SUPPORT SITE USING FREE GOOGLE TOOLS: AN ANALYSIS AND CASE APPLICATION TO DEER MANAGEMENT
}

\author{
G. Kent Webb, San Jose State University, g.webb@sjsu.edu
}

\begin{abstract}
As a case example for the design and implementation of a public decision support site, a variety of free Google tools are applied to supporting deer management decisions. A large number of communities throughout the country are engaged in what is often described as one of the most contentious decisions facing local governments. These decision makers routinely look to the internet for decision support, but information can be contradictory and difficult to find. To determine issues and requirements, data was collected using Google Search, Google keyword data, and a Google Alert was set up to retrieve news and information on the keyword "deer" every day for approximately 10 months. From this information, a support site was constructed using Google sites which makes development easy and free, but which has some restrictions such as a lack of standard database connectivity. As a compromise, the site itself was structured as a hierarchical, knowledge warehouse that could be easily searched using a built-in Google search tool. The results suggest that public policy decisions are being influenced by inaccurate information available on the internet and that keyword search statistics may disguise underlying decision processes so may not be an adequate source of information for site design.
\end{abstract}

Keywords: Knowledge Acquisition Methods, e-Government, Web Design, Public Decision Support, Case Study, Keyword Statistics, Google Tools, Environmental Analysis

\section{INTRODUCTION}

Deer belong to the people of each state. Deer herds are generally managed by state natural resource agencies which have resource limitations. The urban management of deer, which is generally the responsibility of local communities, has become one of the most contentious decisions at the local level. As an effort to develop a web site that can support these public decision makers and their constituents, Google keyword statics and Google Alerts were used to collect data that might help in the requirements analysis, identifying the fundamental issues at question. Using Google Sites and Google Map, a public decision support site was developed that is freely available over the internet.

In a democratic society, decisions are often made by a representative group that may have limited resources to inform their decisions. In the U.S., each congressional representative has a support staff to do research, but the demand for information so far exceeds their capacity that the representatives rely to a large extent on lobbyists who will tend to present only one side of a decision and their support is usually based on who is willing to pay. State and local governments face a similar dilemma, and often resources are more restricted as the represented groups get smaller.

A useful application for academic researchers in information systems could be the development of decision support systems (DSS) to assist in public decision making. Hayen et al [8] provides a definition of a DSS as "the use of the computer to: 1) assist managers with their decision process in semi-structure tasks; 2) to support ...managerial jugdement, ..and 3) to improve the effectiveness of decision making”

\section{Trends in Decision Support Systems Research}

Arnott and Pervan [1] note that publications related to decision support have been falling since its peak of 1994 . From an analysis of the literature they note "a major omission in DSS scholarship is the poor identification of the 
clients and users of the various DSS applications...The analysis of the professional or practical contribution of DSS research shows a field that is facing a crisis of relevance. Half of DSS research was assessed as having low or no practical relevance. Almost half of DSS papers did not use judgment and decision-making reference research. .. "there is a crises of professional relevance ... while DSS publication rate has fallen to early 1990s levels, in practice DSS is one of the only areas of commercial IT that is booming." As an example, they note that common web-based decision support systems are "on websites of most desktop computer-makers, individuals can start with a basic configuration... and then choose different configurations." They suggest that to overcome this disconnect between theory and application, DSS researchers must engage the data warehousing and business intelligence domains. Another suggested strategy for improving the relevance of DSS research is to increase the number of case studies.

Data warehousing and data mining are considered two of the four most important developments in the evolution of Decision Support Systems [15]. The idea of a "knowledge warehouse" can be an extension of the data warehouse that will "not only facilitate the capturing and coding of knowledge, but also enhance the retrieval and sharing of knowledge...”. These researchers suggest this as a new direction for DSS and conclude that the purpose of DSS is "knowledge improvement."

Courtney [3] suggests that DSS researchers should develop decision support systems capable of handling softer information than the typical mathematical models. "The mental models of stakeholders with various perspectives lie at the heart of the decision process, from defining what is a problem, to analysis of the results of trying to solve the problem.”

\section{Web-based Decision Support, Google Sites}

Google has provided a number of free tools that can be applied to creating decision support on the web. Google Sites is an easy to use, free web site with built in editing tools. Storage is limited, but links to items stored in the cloud can be seamlessly integrated into the sites, so the limit on storage need not be a significant obstacle. The number of pages on a site is unlimited, but presentation alternatives are somewhat limited. The research suggests, however, that exotic presentation capabilities are not a requirement for successful development.

An empirical investigation of web-based decision support systems [2] "reveals that the information quality and system quality influence decision-making satisfaction, while information presentation does not have an effect on decision-making satisfaction. " . Shim et al [15] described a trend toward the use of web-based tools to support decision support systems. Power [14] notes that: "Web-based decision support systems... can provide access to multimedia documents and unstructured data.” Google sites makes it easy to integrate multimedia documents, particularly images and YouTube video.

\section{Environmental Decision Support}

Deer management as a collective decision falls into the domain of environmental decision support, since many of the issues have to do with environmental decisions and quality. Ekbia et al [6] provides a detailed case study for the construction a sophisticated, environmental management decision support system for habitat management. The initial plan was to build a knowledge base through a series of workshops with experts. However, the logistics and reluctance of experts to participate in the process proved to be a major barrier to the development of the system. Further the researchers conclude that Decision Support Systems have suffered from a bottoms-up approach, moving from tools and techniques to concepts, but that a top-down approach freed them from a "tyranny of technology", allowing them to view DSS as a collection of tools and methods.

In a later paper Ekbia [5] provides a methodology of steps for development the decision support system, the first of which is problem setting. The outcome of this step would be an outline of major issues and constraints. Matthies, Giupponi, and Bertram [11], examining trends in environmental decision support systems, suggest that future developments should focus on user-friendliness and use in a negotiation or group discussion context. Much of the literature has focused on the use of decision support to facilitate group interaction in public policy issues, and is referred to as social decision support. 
Volume XII, No. 1, pp. 280-290, 2011

\section{Social Decision Support Systems Research}

The phrase Social Decision Support System (SDSS) seems first to have been proposed as "a new type of Information/Communication system or Inquiry System to support the investigation by large groups of complex topics about which many diverse and opposing views are held. The objective of this system is the production, integration, and synthesis of diverse views in a manner in which all participants can come to respect and understand the differences ... and there can be a movement towards consensus on at least some of the issues involved" [17].

Lourenco et al [9] argues in favor of social decision support by noting that "Local policy issues usually exhibit a high degree of complexity and uncertainty and are often characterized as "ill-structured" problems." They propose a new model for e-participation, employing collaborative writing processes to produce agreed upon documents. Yniv and Milyavsky [20] examine how people integrate advice from multiple sources in making social decisions and find people tend to discount information distant from their opinions.

\section{Public Decision Support Systems}

A number of studies that evaluated the role of information systems in e-democracy applications reveal the following limitations: 1) web information is static and represents only one view so a visitor has to visit multiple sites and digest information that is not using a common format and hence is very hard to compare, 2) goal oriented discussions are hard to pursue, 3) the role of participation is unclear [7, 10,19].

The earliest use of the phrase "public decision support system" (PDSS) seems to appear in a 2002 thesis at Eastern Michigan University [12]. Danielson et al [4] provides a case study of developing a public decision support system, making an important distinction as to the requirements of the system based on the type of democratic process. In the "strong democracy" approach, where citizen participation and transparency is important, the focus of the decision support system should be on interactivity to support public discussion. Much of the literature on social decision support systems follows the strong democracy model and so focuses heavily on approaches related to group decision support.

In the thin model type of democratic process "the public is typically consulted only at the policy creation and monitoring stages...the analysis is done by experts in the administration" so the primary role of the PDSS is to provide information [4]. But what information is needed? Previous research has suggested that keyword search statistics can be substituted for more expensive survey research in order to identify information requirements. [18]

\section{RESEARCH METHODOLOGY}

In a effort to see how well keyword search statistics perform as a tool for identifying basic issues and requirements, a research hypothesis to be tested is:

$\mathrm{H}_{1}$ : Google search volume by category will correspond to Google Alerts volume by category for the same search phrase

Google Alerts retrieve news stories every day, providing much more detailed data than keyword search statistics. To test the hypothesis, data for keyword searches related to "deer" were collected using the keyword tool that Google provides for supports its Adwords program (find this tool by typing "google keyword tool” into Google search). The tool identifies average monthly global and local searches for the keyword and related keywords or phrases. Global searches represent all searches, while local searches represent searches in the language of the search entered by the user. Also collected were the results from Google Alerts were collected over a ten month period to build a large collection of textual information related to deer. This collection was combined with standard search techniques to create a detailed text database of deer management cases, news, and information.

Reading through the approximately 50 news stories and other articles returned in the Google Alerts everyday was quite labor intensive. Since some research has indicated that keyword search results can provide a reliable substitute for more expensive survey methods, one goal of this research is to see how much information would be lost by just 
relying on the aggregate keyword statistics to design the content of a decision support site. More broadly, this research question is the reliability of keyword search statistics as a replacement for other research methods. In terms of the case application that motivates this effort, the design of a deer management decision support site, the research questions include: what should be included on the site, what type of information are decision makers looking for, and what are the characteristics of the deer management decision process.

\section{RESULTS}

The average monthly local searches (searches in English) on the keyword 'deer' and related phrases are reported in Table 1. There were about 3.4 million monthly searches in English on the keyword "deer". The most common keyword phrase was "deer hunting", which as reported in the table includes the phrase "deer hunting" and related phrases such as "white-tail deer hunting". Many of the searches related to the term "deer feeding" are also presumably related to deer hunting since hunters often feed deer to attract them or to build up the herd to support hunting. Deer hunting games also scored a large number of searches. Phrases related to deer management, such as “deer Lyme', "deer management”, “deer cars”, and "urban deer management” generally occupy the bottom of the rankings for the number of searches. With only 58 average monthly searches, the phrase "urban deer management" is at the bottom of the ranking for search volume and barely generates enough searches to be included in the search results. By contrast, Table 2 reports the distribution of the news articles and information retrieved using Google Alerts over the ten month collection period. Of the 13,045 articles that were collected, most were not information on deer, but were information on locations such as Deer Valley, on companies such as "Deer Consumer Products", or on other topics where the phrase deer did not specifically refer to deer, the animal. In both Tables 1 and 2, the phrase "Deer Hunting" is the number one result with almost 62 percent of the articles relating to deer hunting.

Table 1. Average Local Monthly Searches on Keywords Related to Deer

\begin{tabular}{|l|c|c|r|}
\hline Keyword & $\begin{array}{l}\text { Ave } \\
\text { Monthly } \\
\text { Searches }\end{array}$ & $\begin{array}{l}\text { Percent of } \\
\text { Searches } \\
\text { on “Deer” }\end{array}$ & Rank \\
\hline Deer & $\begin{array}{c}3,350,00 \\
0\end{array}$ & $100.00 \%$ & \\
\hline Deer Hunting & $\begin{array}{c}2,136,75 \\
0\end{array}$ & $63.78 \%$ & 1 \\
\hline Deer Information & 337,400 & $10.07 \%$ & 2 \\
\hline Deer Pictures & 173,460 & $5.17 \%$ & 3 \\
\hline Deer Feeding & 79,200 & $2.36 \%$ & 5 \\
\hline Deer Lyme & 2,400 & $0.07 \%$ & 11 \\
\hline Deer Tick & 74000 & $2.21 \%$ & 6 \\
\hline Deer Disease & 5400 & $0.16 \%$ & 9 \\
\hline $\begin{array}{l}\text { Deer Hunting } \\
\text { Games }\end{array}$ & 140400 & $4.19 \%$ & 4 \\
\hline $\begin{array}{l}\text { Urban Deer } \\
\text { Management }\end{array}$ & 58 & $0.002 \%$ & 13 \\
\hline $\begin{array}{l}\text { Deer } \\
\text { Management }\end{array}$ & 8100 & \multicolumn{2}{|c|}{0} \\
\hline Deer Cars & 5400 & $0.16 \%$ & 9 \\
\hline Deer Rescue & 1300 & $0.04 \%$ & 12 \\
\hline $\begin{array}{l}\text { Deer Resistant } \\
\text { Plants }\end{array}$ & 9900 & $0.30 \%$ & 7 \\
\hline $\begin{array}{l}\text { Source: Google Keyword Search Data for Average } \\
\text { Monthly Local Searches (Searches in English) From } \\
\text { Google Adwords Tool, Conducted April, 2011 }\end{array}$ \\
\hline
\end{tabular}

As a first step in testing the research hypothesis, an ordinary least squares regression was run using the number of Google Alerts reported in Table 2 as the dependent variable and the average number of keyword searches as 
Volume XII, No. 1, pp. 280-290, 2011

reported in Table 1 as the explanatory variable. The results, reported in Table 3, suggest that the keyword search data significantly predict the Google Alerts; the p-Value for the explanatory variable is well below the typical 0.05 significance level.

Although the regression analysis suggests that the monthly keyword search data significantly predicts the results of the Alerts (news stories), it is clear from a careful review of the data that some significant information would be lost in just relying on the keyword search data. Keyword searches on urban deer management rank at the bottom at $13^{\text {th }}$ for reported keyword results, but in the ranking for Google Alerts, urban deer management ranks third. A review of these stories reveals that these are contentious and complicated decisions often being made with limited information. In general, the topics resulting from the Google Alerts related to deer management are much higher in the rankings than in the results from the keyword searches.

Table 2: Total Google Alerts Related to Keywords

\begin{tabular}{|l|r|r|r|}
\hline Topic & \multicolumn{1}{|c|}{$\begin{array}{l}\text { Google } \\
\text { Alerts }\end{array}$} & $\begin{array}{l}\text { Percent } \\
\text { of Total }\end{array}$ & Rank \\
\hline Deer & 13045 & $100.00 \%$ & \\
\hline Not Relevant* & 8075 & $61.90 \%$ & \\
\hline Deer Hunting & 1264 & $9.70 \%$ & 1 \\
\hline Deer Information & 236 & $1.81 \%$ & 7 \\
\hline Deer Pictures & 90 & $0.69 \%$ & 9 \\
\hline Deer Feeding & 5 & $0.04 \%$ & 12 \\
\hline Deer Lyme & 20 & $0.15 \%$ & 11 \\
\hline Deer Tick & 241 & $0.31 \%$ & 10 \\
\hline Deer Disease & 5 & $1.88 \%$ & 6 \\
\hline $\begin{array}{l}\text { Deer Hunting } \\
\text { Games }\end{array}$ & 829 & $6.35 \%$ & 3 \\
\hline $\begin{array}{l}\text { Urban Deer } \\
\text { Management }\end{array}$ & 925 & $7.09 \%$ & 2 \\
\hline Deer Management & 806 & $6.18 \%$ & 4 \\
\hline Deer Cars & 152 & $1.17 \%$ & 8 \\
\hline Deer Rescue & 351 & $2.69 \%$ & 5 \\
\hline $\begin{array}{l}\text { Deer Resistant } \\
\text { Plants }\end{array}$ & $\begin{array}{l}\mid l \\
\text { *The Not Relevant category includes results such as } \\
\text { locations (Deer Valley), companies (Deer }\end{array}$ \\
$\begin{array}{l}\text { Consumer), and other articles not related to deer, the } \\
\text { animal. }\end{array}$ \\
$\begin{array}{l}\text { Source: Google Alerts Collected Daily from July, } \\
\text { 2010 to April, 2011 }\end{array}$ & & \\
\hline
\end{tabular}

Table 3: Total Alerts as Predicted by Average Monthly Keyword Searches

\begin{tabular}{|l|l|l|}
\hline \multicolumn{3}{|l|}{ OLS Regression Analysis } \\
Dependent Variable: Total Alerts \\
\hline Variable & Coefficient & P-value \\
\hline Intercept & -37.22 & 0.945 \\
\hline Monthly Search & 0.00293 & $0.000007 *$ \\
\hline R Square 0.744 *Significant above 0.01 significance \\
\hline
\end{tabular}

Table 4 shows the results of an ordinal regression indicating that the rank of topics addressed in news stories collected by Google Alerts does not correlate with the rank of keyword searches. After deer hunting, the top ranked topics from Google Alerts were generally related to deer management, a much higher ranking than implied by keyword searches 
Volume XII, No. 1, pp. 280-290, 2011

Table 4: Ordinal Regression for Rank of Total Alerts as Predicted by the Rank of Monthly Keyword Searches

\begin{tabular}{|l|l|l|}
\hline & Chi-Square & Significance \\
\hline Final Model & 0.150 & 0.698 \\
\hline Link function: Logit \\
Not significant
\end{tabular}

While most of the decisions and inquiries driving the Google keyword searches seem to be individual decisions related to deer hunting, such as where should I go to hunt or buy new equipment, the Google Alerts articles focused more on public decisions such as how many hunting licenses should be issues, how should the deer herd of the state be managed, or how should urban deer be managed.

To get an idea of the kinds of public decisions being made with regard to deer management, the Google Alerts articles related to management were examined. In summary, most of the decisions fall into the "thin model" of democracy, mentioned earlier, where citizens provide some input to a decision process, but the decision itself is made by administrators rather than through some election process. At the state level, the Department of Fish and Game or some equivalent state agency makes the deer management decision with professionals or civil servants relying on some input from citizens via public meetings and sometimes websites supporting surveys that collect public opinion.

State agencies typically leave the management of urban deer to local communities, subject to some state constraints on hunting or the use of firearms. Many communities across the nation are involved in these decisions. In terms of the volume of decisions being made, urban deer management accounts for the lion's share, by far. As reported in Table 5, almost all of the decisions are being made by city councils or special committees that report to the city council. A common comment seen in the articles reporting this process is that information is being collected on the internet. Sometimes a state agency will also provide some information support. Table 5 presents the results from examining Google Alerts for 78 communities that are engaged urban deer management

Table 5: Analysis of Google Alerts Related to Urban Deer Management

\begin{tabular}{|c|c|c|}
\hline & Number & Percent \\
\hline Total Communities Making Decisions & 78 & $100 \%$ \\
\hline Decisions Made in City Councils & 70 & $90 \%$ \\
\hline Communities Conducting Deer Surveys & 11 & $14.1 \%$ \\
\hline Communities Conducting Citizen Surveys & 6 & $7.7 \%$ \\
\hline Communities Conducting a Deer Cull & 41 & $52.6 \%$ \\
\hline Communities Considering a Deer Cull & 28 & $35.9 \%$ \\
\hline Issues Cited as the Reason for Considering a Deer Cull * & 28 & \\
\hline Damage to Plants & 62 & $79.5 \%$ \\
\hline Car Accidents & 33 & $42.3 \%$ \\
\hline Lyme Disease & 18 & $23.1 \%$ \\
\hline Number using some sterilization & 3 & $3.8 \%$ \\
\hline Number using some translocation & 5 & $6.4 \%$ \\
\hline
\end{tabular}

Of the 78 communities engaged in urban deer management, only six reported using the results of citizen surveys. One of these surveys was conducted by mail, in the rest of the cases a survey was posted on the community website which tended to attract responses from citizens with strong opinions for or against the deer, making the debate seem more divisive than may have actually been the case. In a few cases, surveys reported that as many as a third of the 
residents were feeding the deer. Several communities discussed the idea of deer surveys to keep track of the deer population, but the cost of these surveys discouraged a number of communities so only about $14 \%$ were keeping track of deer populations using some survey method.

One theme that emerged from these community discussions documented in the Google Alerts is that many residents enjoy watching the urban deer and attach significant value to having deer as part of the suburban landscape. However, the most common issue driving the deer management problem was the destruction of plants in the community, identified as an issue in almost 80 percent of the communities. Deer browse on a large variety of suburban plants, particularly liking roses. Some ecologists have commented that the suburbs are the ideal deer habitat, generally free of predators and filled with what has been described as a deer buffet of tasty plants.

Transportation safety, as reflected in the number of car accidents related to deer, was the second most cited issue with about 42 percent of communities identifying this as a consideration. In the Northeast, many communities were very concerned with Lyme disease. While only 23.1 percent of communities cited this as an issue, it was typically the primary issue in the communities concerned with the spread of Lyme disease.

\section{APPLICATION TO SITE DESIGN}

Since many community decisions are being made by relying on the internet, the decision support site focused on the community level decisions. A frequent comment among decisions makers was that they were looking to see what other communities were doing. However, as the Google Alerts data illustrate, only a small percentage of the searchable information is relevant to the decision. This is also true for the state level decision makers.

As a result, the first objective of the public decision support site was to create an easily searchable knowledge warehouse of articles and information directly related to the deer management decision.

In order to keep costs low, Google sites was used as the platform for the public decision support site. The site is free, offers a limited online editor, and is very easy to use for basic applications. Google sites, however, lacks any useful database connectivity. Since the site offers an unlimited number of pages, each article was given its own page with keyword tags such as "urban”, "disease", and "transportation”, so that a search on the site using a built-in Google tool will yield articles highly relevant to the decision maker. Pages were arranged in a hierarchical data-base structure with information organized by state and then by topic. This format was also expected to be useful for state decision makers who may be interested in knowing about current developments in other states.

As illustrated in Figure 1, each page contains the summary of a news story or article, a link to the original story, links to related stories in each state, and links to a summary or related links for each state. A second objective was to provide a community based deer survey tool that would be an option to providing low-cost surveys of the deer population or problem areas., illustrated by the map in Figure 3. A third objective was to provide support pages for each of the major issues, illustrated in Figure 4 for Lyme disease 
Volume XII, No. 1, pp. 280-290, 2011

Figure 1: Example page from searchable online deer knowledge warehouse

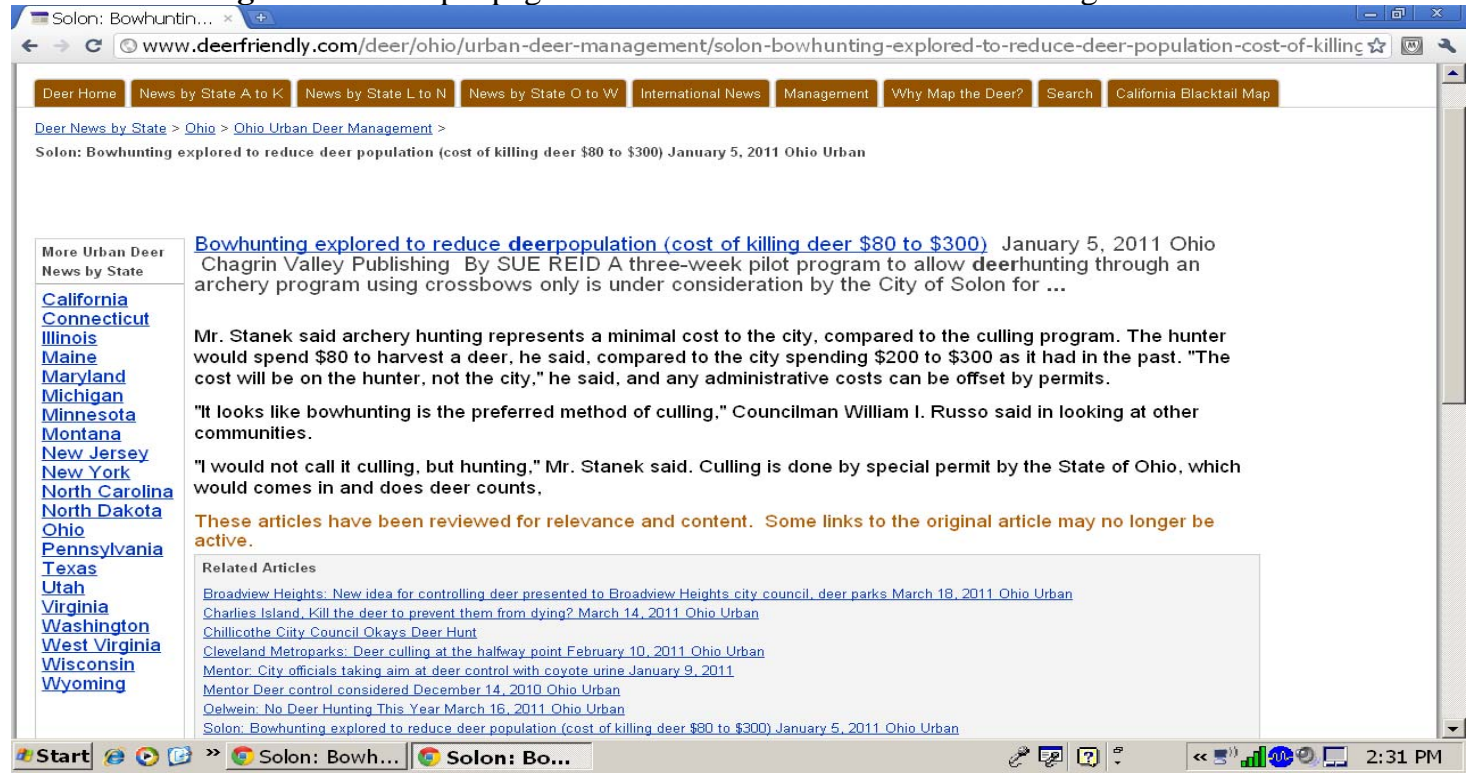

Figure 2: Interactive Deer Map. Clicking on deer icons brings up multimedia information for each site such as articles, video, pictures, and comments. Comments and multimedia documents can be uploaded.

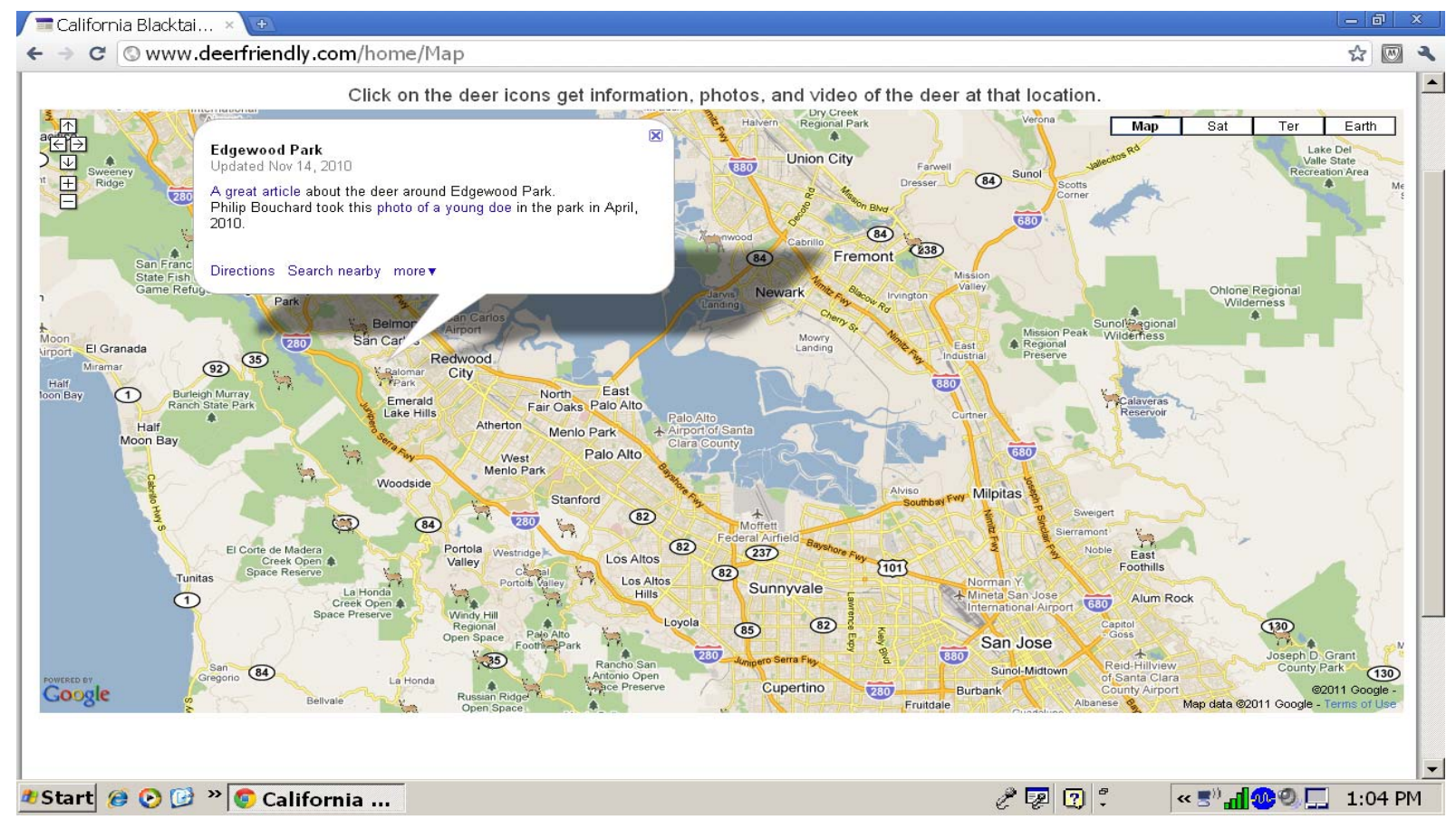


Volume XII, No. 1, pp. 280-290, 2011

Figure 3: Decision Support Page Related to the Deer and Lyme Disease Issue

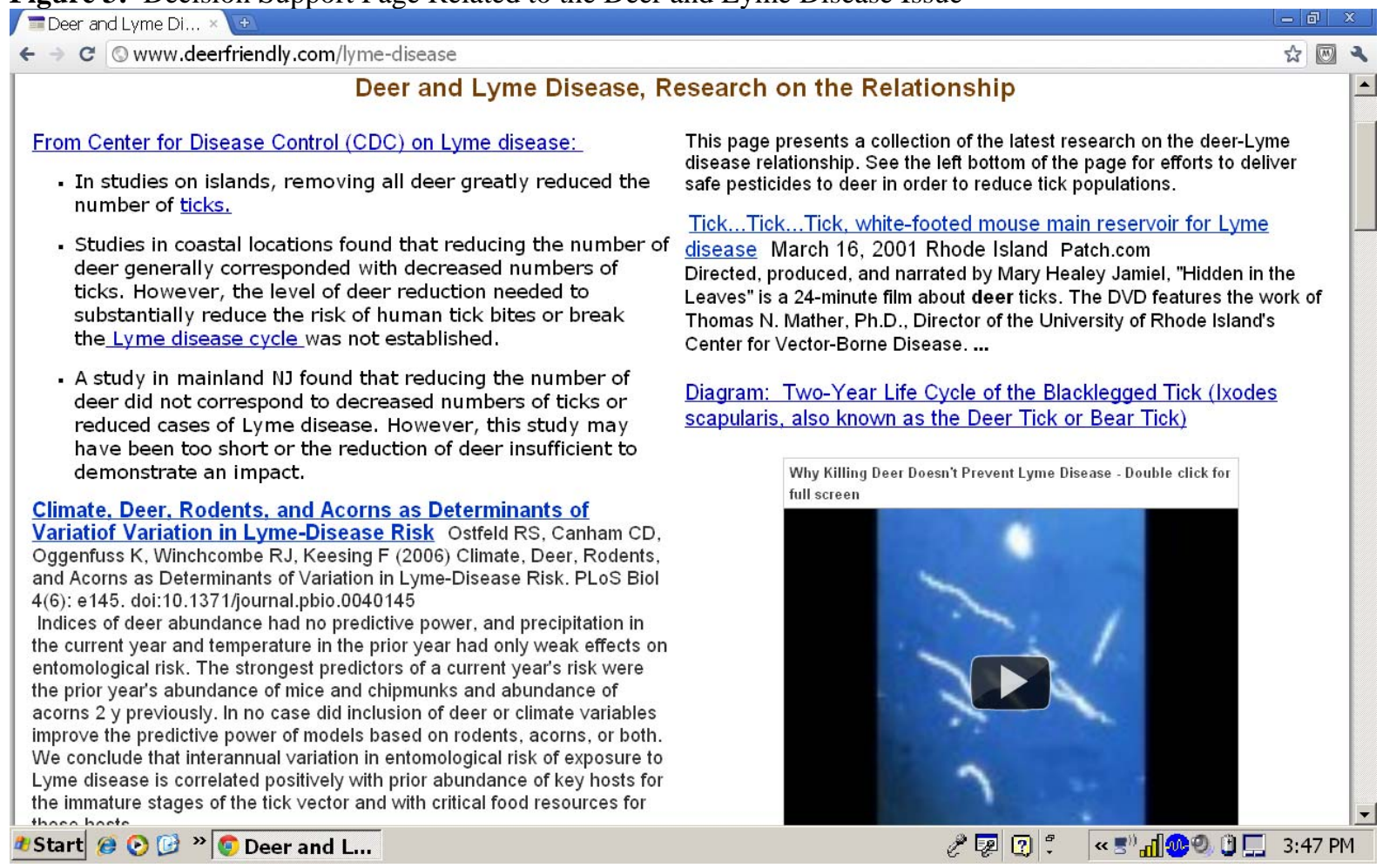

The deer map in Figure 2 can be updated by citizens of the community who can upload information and the location of deer using a form. Pictures, video, and comments are included at each location identified by the deer icon. As illustrated in the figure, clicking on the deer icon identifies the relevant information at each location. This tool has an aspect of group decision support since it allows for citizen participation, but offers that town a survey method with very little associated cost. Several of the communities in the Google Alert survey considered deer surveys and mapping, but discarded them as being too expensive.

Pages for each of the major issues driving the urban deer management decision were created: plant and other ecosystem damage, transportation safety, and Lyme disease. It was discovered that many of the decisions to cull the local deer herd to control Lyme disease were being made on incomplete or inaccurate scientific information. Statements in the press articles indicated that many decision makers believed that deer carry Lyme disease and that “...'there is a direct correlation between the number of deer and the number of infections.' Sullivan explained that ticks feed off the deer, infecting themselves with the disease. They then end up in the grass where they can be transferred to humans. "[16] Although this statement is scientifically inaccurate, deer do not carry Lyme disease, with many research studies cited on the Lyme disease page that contradict this perception, it is representative of the motivation to cull urban deer herds in the 23 percent of the Google Alerts sample where communities identified Lyme disease as a reason for the cull.

One of the leading authorities on Lyme disease and ecology has recently published a book on this topic summarizing his own research and the efforts to reduce the disease by deer hunting. He concludes: "the scientific evidence as I've reviewed it, without any preconceived notion or political agenda or any other agenda, does not support the notion that tick numbers and Lyme disease risk are strongly correlated with deer numbers, and the data do not suggest that if you manage deer by hunting, you'll reduce the number of Lyme cases.” [13] 


\section{Issues in Information Systems}

Volume XII, No. 1, pp. 280-290, 2011

\section{CONCLUSIONS}

Much of the keyword search volume seems to reflect personal decisions and interests, while Google Alerts reflect more community issues appropriate for a newspaper or other news organization. Even though the data is statistically correlated, the public decisions of importance are not well reflected in the keyword search data. In general, relying only on keyword search data in site design may not adequately target the site to the most important issues or information.

Google provides a number of free, useful tools that can be used to develop and analyze web sites. Google Sites is easy to use, but lacks a useful database feature. Structuring the web site as a searchable, hierarchical data base (knowledge warehouse) provides a limited substitute for database functionality. One advantage is that these pages can be found by internet users searching on keywords that are not using the decision support site, attracting visitors to the site who otherwise may not find it.

Decision makers relying on the internet to gather information face a difficult task given the amount of irrelevant information that they must sort through in order to find any relevant information. Unfortunately, some of this information turns out to be inaccurate. Perceptions about deer and Lyme disease seem to have propagated through the internet based on public comments, but not based on scientific evidence. Certainly no academic researchers will be surprised that the web contains much information that is inaccurate, but what may come as a surprise is the extent to which this information is being used in making decisions.

\section{REFERENCES}

1. Arnott, D. and Pervan, G. (2005) A critical analysis of decision support systems research. Journal of Information Technology, 20(2), June, 67-87.

2. Bharati, P. and A. Chaudhury (2004), An emprical investigation of decision-making satisfaction in web-based decision support systems,” Decision Support Systems. 37(3), 187-197

3. Courtney, J.F. (2001). Decision making and knowledge management in inquiring organizations: toward a new decision-making paradigm for DSS, Decision Support Systems, (2).

4. Danielson, M., Ekenbery, L., Gronlund, A.K., and Larson, A. (2005). Public decision support: using a DSS to increase democratic transparency International Journal of Public Information Systems, vol. 1, 1-25.

5. Ekbia, H.R. (2005). Taking decisions to the wild: An AI alperspective in the design of iDMSS. In J. Gupta, G. Forgionne, and M.Mora (eds). Intelligent Decision Support Systems (i-DMSS): Foundations, Applications, and Challenges. Springer Verlag

6. Ekbia, H. R., Davenport, F., Burgess, P., (2011). Rethinking DSS: The case of ccosystem management decision support. The Computer Science Department, The Redlands Institute, University of Redlands, available online at:

http://www.spatial.redlands.edu/sds/downloads/Rethinking\%20DSS\%20The\%20Case\%20for\%20Ecosystem\%2 0Management\%20Decision\%20Support.pdf

7. Gronlund, A (2003). "e-Democracy: in search for tools and methods for effective participation, Journal of Multi-Criteria Decision Analysis, vol. 12, 1-8.

8. Hayen, R. L., Holmes, M. C., and Scott, J. P., (2004). Decision support systems in information technology assimilation. Issues in Information Systems V(2), 481-486

9. Lourenco, R., Costa J.P., (2007). Incorporating citizens views in local policy decision making, Decision Support Systems, 43, 1499-1511

10. Macintosh, A., Davenport, E., Maliina, A., and Whyte, A. (2001). Technology to support participatory democracy, in Ake Gronlund (ed.) Electronic Government - Design, Application, and Management. Idea Group Publishiing.

11. Matthies, M., Giupponi, C., and Ostendorf, B., (2007). Environmental decision support systems: Current issues, methods and tools. Environmental Modelling \& Software 22(2), 123-127

12. Mullins, T. J. (2002). Issues in online public decision support system design Eastern Michigan University Thesis

13. Ostfeld, Richard S. (2011). Lyme Disease: The Ecology of a Complex System. Oxford University Press 
14. Power, D.J. (1998). Web-based decision support systems, On-Line Executive Journal for Data-Intensive Decision Support 2(34)(Aug.) www.tgc.com/dsstar

15. Shim, J.P, Warkentin, M., Courtney,J.F., Power, D.J., Sharda, R., Carlsson, C. (2002). Past, present, and future of decision support systems. Decision Support Systems, 33, 111-126

16. Sullivan, Michael; Medfield Town Administrator (2011). "Medfield to 'cull the herd' with archers to combat the spread of Lyme” Medfield Press, Online, February 22, 2011

17. Turoff, M., Hiltz. S.R., Cho, H.K., Li, Z., and Wang, Y., (2002). Social decision support systems,” presented at $35^{\text {th }}$ Hawaii International Conference on Systems Sciences, Hawaii.

18. Webb, G.K. (2007). Analysis of pages and metrics related to global environmental management. Issues in Information Systems (9)2. 111-116

19. Wilhelm, A.G. (2000). Democracy in the digital age. Challenges to political life in cyberspace. Routledge.

20. Yaniv, I., and Milyavsky, M. (2005). Using advice from multiple sources to revise and improve judgements. Organizational Behavior and Human Decision Processes. 103(1). 104-120. 